\title{
Detection of Toxoplasma gondii oocysts in water: proposition of a strategy and evaluation in Champagne-Ardenne Region, France
}

\author{
D Aubert, I Villena ${ }^{+}$ \\ Laboratoire de Parasitologie-Mycologie, EA 3800, Centre National de Référence de la Toxoplasmose, CHU Maison Blanche, \\ UFR Médecine, IFR53, 45 rue Cognacq-Jay, 51092 Reims Cédex, France
}

\begin{abstract}
Water is a vehicle for disseminating human and veterinary toxoplasmosis due to oocyst contamination. Several outbreaks of toxoplasmosis throughout the world have been related to contaminated drinking water. We have developed a method for the detection of Toxoplasma gondii oocysts in water and we propose a strategy for the detection of multiple waterborne parasites, including Cryptosporidium spp. and Giardia. Water samples were filtered to recover Toxoplasma oocysts and, after the detection of Cryptosporidium oocysts and Giardia cysts by immunofluorescence, as recommended by French norm procedure NF T 90-455, the samples were purified on a sucrose density gradient. Detection of Toxoplasma was based on PCR amplification and mouse inoculation to determine the presence and infectivity of recovered oocysts. After experimental seeding assays, we determined that the PCR assay was more sensitive than the bioassay. This strategy was then applied to 482 environmental water samples collected since 2001. We detected Toxoplasma DNA in 37 environmental samples (7.7\%), including public drinking water; however, none of them were positive by bioassay. This strategy efficiently detects Toxoplasma oocysts in water and may be suitable as a public health sentinel method. Alternative methods can be used in conjunction with this one to determine the infectivity of parasites that were detected by molecular methods.
\end{abstract}

Key words: Toxoplasma gondii oocyst - filtration - purification - molecular detection

Many classes of pathogens excreted in animal and humans faeces are responsible for waterborne disease. Enteric viruses and protozoans are known to cause outbreaks similar to enteric bacterial agents, which are the main cause of outbreaks disease worldwide. Protozoan agents are very robust in water environments and are strongly resistant to most disinfectants, including chemical procedures (like chlorination) used to disinfect drinking water. Over the last 30 years, giardiasis has become the most common cause of human waterborne disease in the United States (Furtado et al. 1998, Karanis \& Kourenti et al. 2007). However, waterborne cryptosporidiosis outbreaks have also been reported during that time, including one in Milwaukee in 1993 affecting 403,000 people (Mc Kenzie et al. 1994). The majority of reported parasitic outbreaks occurred where water samples were negative for coliform bacteria, demonstrating that water treatment technologies and water quality controls were inadequate to assess parasitic risk.

Toxoplasmosis is a common infection transmitted primarily by the consumption of raw or undercooked meat containing tissue cysts, but also potentially by the ingestion of vegetables or water contaminated with sporulated oocysts (Tenter et al. 2000). Felids are the only known hosts that can release oocysts into the environment in their faeces (Dubey \& Beattie 1988). Toxoplasmosis is present throughout the world, especially in Europe (pri-

+ Corresponding author: ivillena@chu-reims.fr

Received 10 October 2008

Accepted 13 March 2009 marily Southern Europe), South and Central America and Africa. Infections occurring in immunocompetent persons are usually without symptoms or benign; however, infections can be severe in cases of maternal transmission to the foetus, leading to congenital infection, and in immunocompromised patients. Several waterborne toxoplasmosis outbreaks have been documented. The first occurred in Panama, in 1979, with the infection of 39 soldiers who used three water sources for their drinking water. Contaminated jungle streams were determined to be the most likely source of Toxoplasma infection, in the absence of other identifiable common exposures (Benenson et al. 1982). In 1995, a large waterborne outbreak occurred in British Colombia, with 100 individuals infected with toxoplasmosis due to consumption of contaminated drinking water (Bowie et al. 1997). A municipal water system that used unfiltered and chloraminated surface water was the likely source of contamination by cougar and/or domestic cat faeces (Aramini et al. 1999). In 1999, drinking water was also reported as the vehicle of infection among Jains, a community of strict vegetarians (Hall et al. 1999). The largest outbreak, with 290 human cases, was more recently reported in Brazil and involved an unfiltered water reservoir (Keenihan et al. 2002). Moreover, a high Toxoplasma prevalence related to drinking unfiltered water was found in Brazilian communities (Bahia-Oliveira et al. 2003). Likewise, a large toxoplasmosis outbreak in 2000 was associated with the consumption of contaminated water from a municipal reservoir, which was vulnerable to infiltration due to its precarious state of conservation. Interestingly, water collected from the suspected reservoir was filtered and multiple bioassays were performed in cats, chickens and pigs fed with the membrane filters, leading to parasite 
isolation and genotyping (De Moura et al. 2006). The last outbreak was the only one in which detection of $T$. gondii in the implicated water source was possible. As Toxoplasma oocysts are very resistant to environmental conditions (Dubey 1998), increased awareness of the risk of waterborne toxoplasmosis outbreaks has led to the development of methods that can efficiently detect oocysts in environmental water.

\section{MATERIAL AND METHODS}

We have developed a strategy for the recovery and detection of oocysts and cysts, including those of Toxoplasma gondii, Cryptosporidium spp., and Giardia, which are the main parasites associated with waterborne outbreaks (Villena et al. 2004). Briefly, after the filtration of large volumes (25-100 L) of environmental samples using Envirocheck capsules (Pall Life Sciences), particulate matter was eluted from the capsule filter (1 $\mu \mathrm{m}$ absolute pore size) with an elution buffer containing detergents (Tween-80 and Laureth-12, Pall Life Sciences). Eluates were then centrifuged and the pellet was subjected to immunomagnetic separation (IMS) to detect Giardia cysts and Cryptosporidium oocysts. These parasites were detected by immunofluorescence methods using a method adapted from Method 1623 of the USEPA (1999), as described in French norm procedure NF T 90-455 (AFNOR). After this step, the eluate was centrifuged, the supernatant discarded and the pellet suspended in a sucrose suspension (density 1.15). After another centrifugation, $2 \mathrm{~mL}$ of this supernatant was collected and mixed with $8 \mathrm{~mL}$ of deionised water. Then, a final centrifugation was performed in order to collect sediment for Toxoplasma oocyst detection. For this, the sediment was separated into two parts, one for PCR amplification and another for the bioassay after sporulation in $2 \%$ aqueous $\mathrm{H}_{2} \mathrm{SO}_{4}$ in an aerated tube ( $\mathrm{rt}$ for 7 days).

PCR detection - The sediment was resuspended in 1 $\mathrm{mL}$ of Tris-EDTA buffer and centrifuged, three cycles of freezing- thawing $\left(-80^{\circ} \mathrm{C}\right)$ were performed and the pellet was then subjected to proteinase $\mathrm{K}$ digestion $\left(1 \mathrm{~h}\right.$ at $\left.60^{\circ} \mathrm{C}\right)$. DNA extraction was performed with QIAmp DNA minikits (Qiagen, France), followed by real-time PCR. The T. gondii $\mathrm{B} 1$ gene was detected with Taqman probe $(10$ $\mathrm{pmoL} / \mu \mathrm{L})$ 6FAM-TCTGTGCAACTTTGGTGTATT-CGCAG-TAMRA (Lin et al. 2000) and the $A F 487550$ gene was detected with Taqman probe $(10 \mathrm{pmoL} / \mu \mathrm{L}) 6 \mathrm{FAM}$ TAGATAGTCGAAAGGGAAAC-TAMRA (Homan et al. 2000). To detect PCR inhibitors, DNA from a mimetic plasmid insert $(1 \mathrm{pg} / \mathrm{mL})$ was added in a second run in all environmental samples. In case of the presence of inhibitors, $8 \mu \mathrm{g}$ of bovine serum albumin (BSA, Boehringer, Germany) was added to a new reaction mixture before the next amplification (Villena et al. 2004).

Bioassay - The aerated suspension was neutralized by adding 3.3\% sodium hydroxide and then centrifuged and the sediment was resuspended in $1.5 \mathrm{~mL}$ of normal saline suspension containing antibiotics. Female SwissWebster mice (negative to Toxoplasma serology) were inoculated by gavages and seroconversion was deter- mined after four weeks and confirmed by examination of sacrificed mice, in case of positive case.

\section{RESULTS}

Over the course of seven years, we collected environmental water samples in sites selected by health officials in the Champagne-Ardenne Region. Of these sites, five corresponded to departments of the region, one to the District of Reims, and one to a river. A total of 482 samples were analysed. These consisted of raw surface water $(\mathrm{RSW})(\mathrm{n}=100)$ collected near waterplant intakes or in a river crossing the district that was chosen because of its constant positivity, underground water (UW) $(n=$ $263)$ and public drinking water $(\mathrm{PDW})(\mathrm{n}=119)$. Samples from different geographical locations exhibited a range of turbidities, measured by the nephelometric procedure. The filtered volumes were variable depending on the turbidity and nature of the water: 5-45 L of RSW, 25-100 L of UW and $100 \mathrm{~L}$ of PDW.

We detected Cryptosporidium oocysts in 92 samples, Giardia cysts in 101 samples, and T. gondii oocysts in 37 samples. There was no correlation between $T$. gondii presence in environmental water and the presence of Cryptosporidium or Giardia. Among the 469 samples not containing PCR inhibitors, 432 were negative. Thirteen samples were found to contain PCR inhibitors. After adding BSA, eight samples were found to be negative, three positive and two samples remained uninterpretable. The last two were either true negatives or contained an excessive amount of PCR inhibitors. None of the samples positive for Toxoplasma DNA were positive in the bioassay. These results are shown in Table, with results from each site according to the nature of the water samples (UW, raw surface and PDW).

\section{DISCUSSION}

Water has been considered to be an important vehicle for disseminating human toxoplasmosis, as $T$. gondii oocysts can persist for a long time in the environment (Dubey 1998) and are highly resistant to the various inactivation procedures based on chemical reagents and disinfection processes used by water utilities (Dubey et al. 1970, 1998). Prior to this study, several methods had been described for the recovery and detection of $T$. gondii oocysts in contaminated water (Isaac-Renton et al. 1998, Dumètre \& Dardé 2003, Kourenti \& Karanis 2004, Sotiriadou \& Karanis 2008). These methods were not as well established as the ones described for the recovery and detection of Cryptosporidium and Giardia. The standard methods currently available for the detection of these parasites in water include the concentration-filtration of large volumes, elution and purification on density gradients or by IMS, and finally detection by immunofluorescence assay using monoclonal antibodies (Quintero-Betancourt et al. 2002). Often, however, these methods for the detection of waterborne protozoa were reported in laboratory conditions with high inoculums in seeding experiments, but not in natural samples. We have developed a method for the detection of Toxoplas$m a$ oocysts in environmental water that can be combined with assays to detect Cryptosporidium and Giardia in 


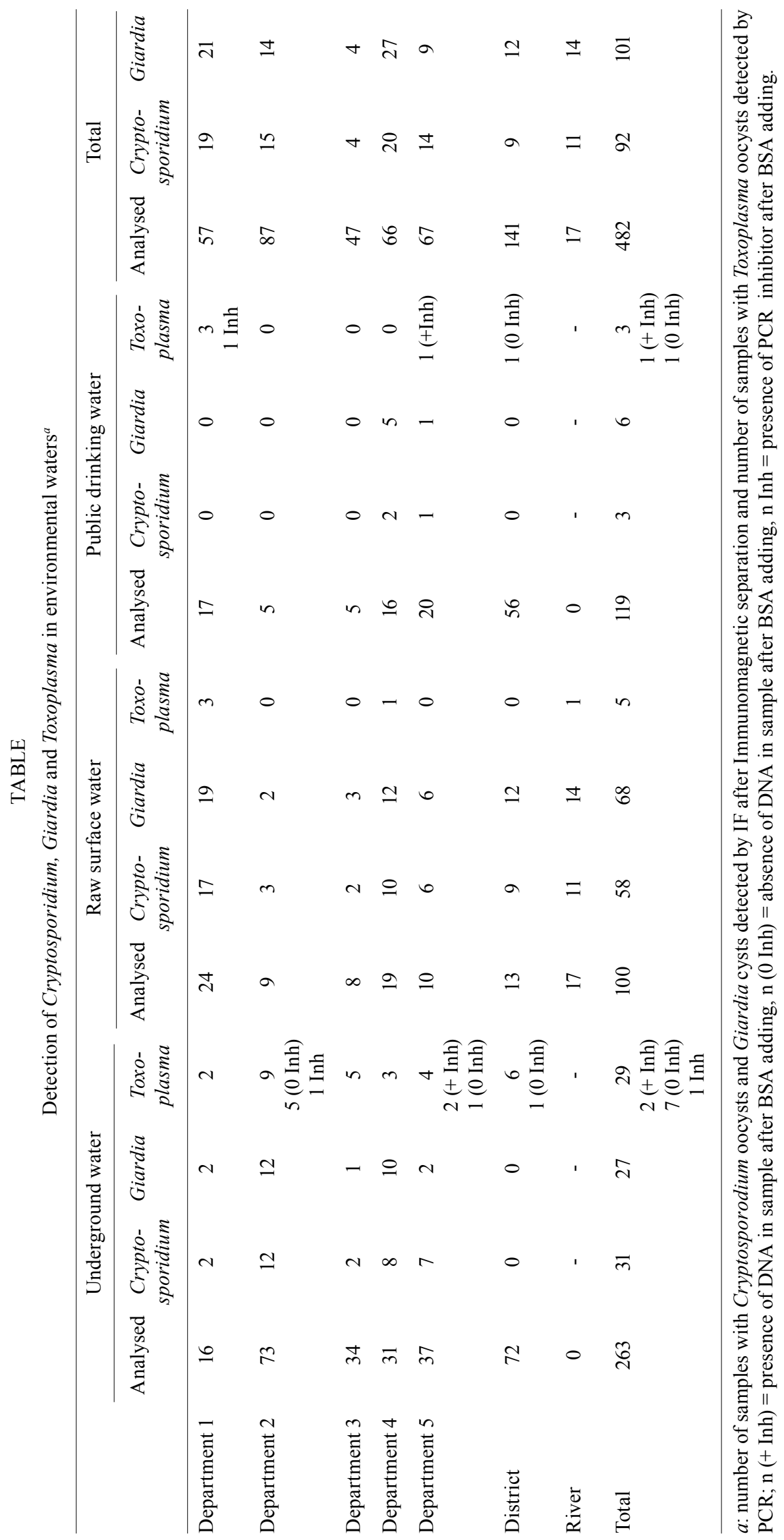


the same sample, simplifying the procedure for health authorities (Villena et al. 2004).

The concentration-filtration step is critical, as it is marked by the loss of seeded oocysts. While flocculation is simple, inexpensive, and has high recovery rates in tap water (Kourenti et al. 2003), filtration appears to be more robust for processing turbid water. Envirochek capsules (Pall Life Sciences) consist of a polyethersulfonate membrane with a $1 \mu \mathrm{m}$ absolute pore size, allowing for the filtration of most waterborne agents and the elimination of debris and most PCR inhibitors present in environmental samples (Matheson et al. 1998). Because there are few target organisms in the samples (due to dilution in water), capsules offer a large volume of filtration (100-500 L) and are commonly used in to detect Cryptosporidium and Giardia even in highly turbid water (USEPA 1999), as well as Cyclospora oocysts (Sturbaum et al. 1998), which are close in size of Toxoplasma (size around $10 \mu \mathrm{m}$ ). After filtration, elution buffers with detergents (Laureth-12, Tween-80, or sodium dodecyl sulphate) are necessary to recover protozoa present in the filter (Quintero-Betancourt et al. 2002). Following the concentration step, Toxoplasma oocysts should be purified using sucrose flotation (specific gravity $\geq$ 1.15), a commonly used method yielding a large number of purified oocysts (Dubey et al. 1970). Recently, Sheather's sugar solutions with specific gravities of 1.07 and 1.11 have been reported to recover $78-100 \%$ of sporulated or unsporulated Toxoplasma oocysts, depending on the amounts of contaminating debris (Kourenti \& Karanis 2006). It was also demonstrated that old and/or degenerated oocysts exhibited greater densities $(>1.10)$ than fresh oocysts (Dumètre \& Dardé 2004), which could explain the differences in recovery rates depending on oocyst viability. IMS or fluorescence-activated cell sorting (FACS) may also be employed to improve purification, resulting in a better preparation - these techniques were used for Cryptosporidium and Giardia detection in environmental waters with good recovery rates (Rochelle et al. 1999). Recently, specific IMS for Toxoplasma was developed using a monoclonal antibody produced against the oocyst wall (mAb 3G4). Mean oocyst recoveries from this technique ranged from $45-83 \%$ in experimental conditions, depending on the incubating temperature and buffer (Dumètre \& Dardé 2005). Using another monoclonal antibody (mAb 4B6) targeting the sporocyst wall of multiple organisms related to Toxoplasma, IMS was tested under different conditions and sporocyst recoveries ranged from $14-45 \%$ in drinking water samples spiked with 1-10 oocysts/L, and from $18-32.5 \%$ in surface water samples spiked with 10 oocysts/L (Dumètre \& Dardé 2007). However, due to $\mathrm{mAb}$ 4B6 cross-reactions, PCR amplification was necessary after IMS to characterize coccidian sporocysts detected microscopically. This method could be efficient for isolating Toxoplasma oocysts, but its effectiveness in environmental waters remains to be evaluated.

The next step was the detection of purified oocysts. Rapid and sensitive pathogen detection methods are essential for the public water industry and public health authorities. PCR has been described as more sensitive and specific than conventional methods of detection for Cryptosporidium detection in environmental waters (Fontaine \& Guillot 2003). We adapt this strategy for Toxoplasma detection, as there are no commercial immunofluorescence kits available to detect Toxoplasma oocysts, and PCR should be able to detect low parasite numbers in environmental waters (Schwab \& McDevitt 2003, Sotiriadou \& Karanis 2008). In this study, the PCR sensitivity ranged from 1 oocyst/L up to 1000 oocysts/L, depending on the source of seeded water (the best sensitivity was obtained with deionised water). Moreover, PCR was more sensitive than the bioassay by mice inoculation (Villena et al. 2004). Schwab and McDevitt (2003) have developed a PCR method capable of detecting fewer than 50 oocysts in experimental conditions. In addition, Sotiriadou and Karanis (2008) have recently developed a loop-mediated isothermal amplification (LAMP)-specific protocol to amplify Toxoplasma DNA with better results than nested PCR. DNA extraction is critical, as the oocyst wall is very robust. Different methods have been proposed, including freeze-thawing, grinding with glass beads or sonication and lengthy proteinase $\mathrm{K}$ digestion (Dumètre \& Dardé 2003). However, since there is no standard protocol and no optimal conditions have been identified to destroy the oocyst wall, we choose freeze-thawing followed by proteinase $\mathrm{K}$ digestion for its simplicity and speed. In environmental conditions, numerous substances such as humic acids have been identified as PCR inhibitors. Processes such as IMS or FACS are often sufficient to purify the sample, but PCR inhibitors may be not completely removed by flotation procedures. Thus, we add BSA to reduce the incidence of inhibitors in our samples, as suggested by Rochelle et al. (1997). We have already demonstrated the efficiency of this procedure for environmental water samples (Villena et al. 2004); however, PCR inhibitors are still present in some environmental samples (Kourenti \& Karanis 2006). Here, using BSA allowed us to remove PCR inhibitors from 11 of 13 samples, with the positive detection of Toxoplasma in three.

Under our conditions, we detected Toxoplasma in $7.7 \%$ of water samples collected during a seven-year period. Sotiriadou and Karanis (2008) recently reported positive samples in $48 \%$ of 52 natural water samples using a LAMP-specific protocol targeting the $T g O W P$ and B1 Toxoplasma genes. Cryptosporidium and Giardia were always detected in higher numbers than Toxoplasma and both pathogens are more often present in raw surface or UW than in PDW. Contamination in RSW is not surprising, as environmental matrices may be contaminated by soil washing after peaks in rainfall, as described by Bowie et al. (1997). Contamination was likely present in UW because of the vulnerability of these resources and the fact that these samples were chosen by local public health officials because of frequent pathogen recovery (coliform) or high turbidity levels. This frequency in the detection of major parasites has already been reported (Slifko et al. 2000). Giardia and Cryptosporidium are more ubiquitous in nature because of their excretion by a wide range of hosts, while Toxoplasma oocysts are only excreted by felids. Waterborne outbreaks due to Giardia 
and Cryptosporidium in PDW have been reported even when sanitary controls were satisfactory (with no bacterial pathogens). The presence of Toxoplasma DNA in three PDW samples is more surprising, since none of those samples were positive by bioassay. The bioassay is the reference test for Toxoplasma isolation since it is positive in the presence of viable parasites and can be used for genotyping (De Moura et al. 2006), but this method is time and cost consuming. In addition, the bioassay is less sensitive for the detection of Toxoplasma in environmental samples, as demonstrated by Isaac-Renton et al. (1998). These authors proposed the use of this assay to detect Toxoplasma oocysts in environmental samples with same rates of detection as observed in sterile saline $(2.5$ oocysts/L). Moreover, they failed to detect oocysts in raw water samples. Recently, a bioassay performed on pigs and cats was found to be effective for the isolation of Toxoplasma oocysts in water samples (De Moura et al. 2006).

DNA amplification may be due to the detection of dead oocysts (explaining the divergence with the bioassay) and tests for the identification of viable oocysts may be developed in the future. To assess the viability of $\mathrm{Gi}$ ardia cysts and Cryptosporidium oocysts, inclusion of DAPI or exclusion of propidium iodide have been used, but these methods are not applicable to Toxoplasma oocysts, probably due to differences in wall composition (Dumètre \& Dardé 2003). To determine the viability of Toxoplasma oocysts, reverse transcription (RT)-PCR was in development in our laboratory, but mRNA detection seems less sensitive in the presence of PCR inhibitors in samples (data not shown). Since the bioassay takes too long for public health sentinel purposes, continued efforts are necessary to develop rapid tests able to differentiate between viable and nonviable oocysts present in environmental samples.

In conclusion, waterborne parasitic disease is an emergent problem. Although methods to detect Cryptosporidium oocysts and Giardia cysts have been available for several years, methods are still in development to detect Toxoplasma oocysts in environmental samples and especially in water, a possible source of human infection. The IMS method using monoclonal antibodies developed against the oocyst wall and PCR detection could be acceptable strategies, as they have been employed for other parasites in the environment. The LAMP amplification method could also be used in this strategy. In addition, methods to detect the principal parasites responsible for waterborne outbreaks (i.e Cryptosporidium, Giardia and Toxoplasma) could be combined to create a survey strategy for public health authorities. Moreover, RT-PCR by real time or by LAMP amplification could be developed to determine the viability of Toxoplasma oocysts in place of the bioassay, which is more time consuming.

\section{ACKNOWLEDGEMENTS}

To the District of Reims, DRASS of Region Champagne Ardenne, and DDASS (Aisne, Ardennes, Aube, Marne, HauteMarne) for their collaboration in this program, and to F. Marnef, R. Geers and E. Pisano, for their technical participation.

\section{REFERENCES}

Aramini JJ, Stephen C, Dubey JP, Engelstoft C, Schwantje H, Ribble CS 1999. Potential contamination of drinking water with Toxoplasma gondii oocysts. Epidemiol Infect 122: 305-315.

Bahia-Oliveira LM, Jones JL, Azevedo-Silva J, Alves CC, Oréfice F, Addiss DG 2003. Highly endemic waterborne toxoplasmosis in North Rio de Janeiro State, Brazil. Emerg Infect Dis 9: 55-62.

Benenson MW, Takafuji ET, Lemon SM, Greenup RL, Sulzer AJ 1982. Oocyst-transmitted toxoplasmosis associated with ingestion of contaminated water. $N$ Engl J Med 307: 666-669.

Bowie WR, King AS, Werker DH, Isaac-Renton JL, Bell A, Eng SB, Marion SA 1997. Outbreak of toxoplasmosis associated with municipal drinking water. Lancet 350: 173-177.

De Moura L, Bahia-Oliveira LM, Wada MY, Jones JL, Tuboi SH, Carmo EH, Ramalho WM, Camargo NJ, Trevisan R, Graça RM, da Silva AJ, Moura I, Dubey JP, Garrett DO 2006. Waterborne toxoplasmosis, Brazil, from field to gene. Emerg Infect Dis 12: 326-329.

Dubey JP 1998. Toxoplasma gondii oocysts survival under defined temperatures. J Parasitol 84: 862-865.

Dubey JP, Beattie CP 1988. Toxoplasmosis of animals and man, CRC Press, Boca Raton, 220pp.

Dubey JP, Miller NL, Frenkel JK 1970. Characterization of the new fecal form of Toxoplasma gondii. J Parasitol 56: 447-456.

Dubey JP, Thayer DW, Speer CA, Shen SK 1998. Effect of gamma irradiation on unsporulated and sporulated Toxoplasma gondii oocysts. Int J Parasitol 28: 369-75.

Dumètre A, Dardé ML 2003. How to detect Toxoplasma gondii oocysts in environmental samples? FEMS Microbiol Rev 27: 651-661.

Dumètre A, Dardé ML 2004. Purification of Toxoplasma gondii oocysts by cesium chloride gradient. J Microbiol Methods 56: 427-430.

Dumètre A, Dardé ML 2005. Immunomagnetic separation of Toxoplasma gondii oocysts using a monoclonal antibody directed against the oocysts wall. J Microbiol Meth 61: 209-217.

Dumètre A, Dardé ML 2007. Detection of Toxoplasma gondii in water by an immunomagnetic separation method targeting the sporocysts. Parasitol Res 101: 989-996.

Fontaine M, Guillot E 2003. An immunomagnetic separation-realtime PCR method for quantification of Cryptosporidium parvum in water samples. J Microbiol Methods 54: 29-36.

Furtado C, Adak GK, Stuart JM, Wall PG, Evans HS, Casemore DP 1998. Outbreaks of waterborne infectious intestinal disease in England and Wales, 1992-5. Epidemiol Infect 121: 109-119.

Hall SM, Pandit A, Golwilkar A, Williams TS 1999. How do Jains get Toxoplasma infection? Lancet 354: 486-487.

Homan WL, Vercammen M, De Braekeleer J, Verschueren H 2000. Identification of a 200 to 300 -fold repetitive 529 bp DNA fragment in Toxoplasma gondii, and its use for diagnostic and quantitative PCR. Int J Parasitol 30: 69-75.

Isaac-Renton J, Bowie WR, King A, Irwin GS, Ong CS, Fung CP, Shokeir MO, Dubey JP 1998. Detection of Toxoplasma gondii oocysts in drinking water. Appl Environ Microbiol 64: 2278-2280.

Karanis P, Kourenti C, Smith H 2007. Waterborne transmission of protozoan parasites: a worldwide review of outbreaks and lessons learnt. $J$ Water Healt 5: 1-38.

Keenihan SH, Schetters T, Taverne J 2002. Toxoplasma in Brasil. Trends Parasitol 18: 203-204. 
Kourenti C, Heckeroth A, Tenter A, Karanis P 2003. Development and application of different methods for the detection of Toxoplasma gondii in water. Appl Environ Microbiol 69: 102-106.

Kourenti C, Karanis P 2004. Development of a sensitive polymerase chain reaction method for the detection of Toxoplasma gondii in water. Water Sci Technol 50: 287-291.

Kourenti C, Karanis P 2006. Evaluation and applicability of a purification method coupled with nested PCR for the detection of Toxoplasma oocysts in water. Lett Appl Microbiol 43: 475-481.

Lin MH, Chen TC, Kuo TT, Tseng CC, Tseng CP 2000. Real-time PCR for quantitative detection of Toxoplasma gondii. J Clin Microbiol 38: 4121-4125.

Matheson Z, Hargy TM, McCuin RM, Clancy JL, Fricker C 1998. An evaluation of the Gelman envirochek capsule for the simultaneous concentration of Cryptosporidium and Giardia from water. $J$ Appl Microbiol 85: 755-761.

Mc Kenzie WR, Hoxie N, Proctor ME, Gradus MS, Blair KA, Peterson DE, Kazmierczak JJ, Addiss DG, Fox KR, Rose JB 1994. A massive outbreak in Milwaukee of Cryptosporidium infection transmitted through the public water supply. $N$ Engl J Med 331: 161-167.

Quintero-Betancourt WE, Peele ER, Rose JB 2002. Cryptosporidium parvum and Cyclospora cayetanensis: a review of laboratory methods for detection of theses waterborne parasites. J Microbiol Methods 49: 209-224.

Rochelle PA, De Leon R, Johnson A, Stewart MH, Wolfe RL 1997. Comparison of primers and optimisation of PCR conditions for detection of Cryptosporidium parvum and Giardia lamblia in water. Appl Environ Microbiol 63: 106-114.
Rochelle PA, De Leon R, Johnson A, Stewart MH, Wolfe RL 1999. Evaluation of immunomagnetic separation for recovery of infectious Cryptosporidium parvum oocysts from environmental samples. Appl Environ Microbiol 65: 841-845.

Schwab KJ, McDevitt JJ 2003. Development of a PCR-enzyme immunoassay oligoprobe detection method for Toxoplasma gondii oocysts, incorporating PCR controls. Appl Environ Microbiol 69: $5819-5825$

Slifko TR, Smith HV, Rose JB 2000. Emerging parasite zoonoses associated with water and food. Int J Parasitol 30: 1379-1393.

Sotiriadou I, Karanis P 2008. Evaluation of loop-mediated isothermal amplification for detection of Toxoplasma gondii in water samples and comparative findings by polymerase chain reaction and immunofluorescence test (IFT). Diagn Microbiol Infect Dis 62: 357-365.

Sturbaum GD, Ortega YR, Gilman RH, Sterling CR, Cabrera L, Klein DA 1998. Detection of Cyclospora cayetanensis in wastewater. Appl Environ Microbiol 64: 2284-2286.

Tenter AM, Heckeroth AR, Weiss LM 2000. Toxoplasma gondii: from animals to humans. Int J Parasitol 30: 1217-1258.

USEPA 1999 Method 1623: Cryptosporidium and Giardia in water by filtration/IMS/FA. Office of water EPA-821-R-99-006.

Villena I, Aubert D, Gomis P, Ferté H, Inglard JC, Denis-Bisiaux H, Dondon JM, Pisano E, Ortis N, Pinon JM 2004. Evaluation of a strategy for Toxoplasma gondii oocyst detection in water. Appl Environ Microbiol 70: 4035-4039. 